\title{
A construção social do conceito infância no sistema capitalista: um levantamento bibliográfico
}

\section{The social construction of the childhood concept in the capitalist system: a bibliographic survey}

\author{
Idelvani da Conceição Bezerra Thiago ${ }^{1}$ \\ Maria Nilvane Fernandes ${ }^{2}$
}

\section{Resumo}

O presente estudo objetiva discutir a construção ideológica da concepção de infância a partir da perspectiva histórico-crítica. $\mathrm{O}$ debate articula-se com a seguinte problematização: Quais interesses políticos, econômicos e sociais ligados à formulação do conceito de infância tornaram o termo uma construção social hegemônica no sistema capitalista? Nesse intento, realizamos pesquisa bibliográfica e documental para atender aos seguintes objetivos específicos: a) categorizar, nos repositórios, como o termo infância tem sido identificado nas linhas acadêmicas, a partir das principais bibliografias utilizadas; b) identificar as fontes documentais utilizadas nas pesquisas selecionadas; e c) classificar em eixos as pesquisas destacadas. A pesquisa do tema surge da necessidade de se investigar a diferença entre os termos criança e infância, situando-se historicamente a concepção e os novos contornos em relação aos conceitos.

Palavras-chave: Criança; Infância; Construção social.

\begin{abstract}
This study aims to discuss the ideological construction of the conception of childhood from a historical-critical perspective. The debate is articulated with the following problematization: What political, economic and social interests linked to the formulation of the concept of childhood made the term a hegemonic social construction in the capitalist system? With this in mind, we carried out a bibliographical and documentary research to meet the following specific objectives: a) categorize, in repositories, how the term childhood has been identified in academic lines, based on the main bibliographies used; b) identify the document sources used in the selected researches; and c) classify the highlighted researches into axes. The research on the theme arises from the need to investigate the difference between the terms child and childhood, historically situating the conception and the new contours in relation to the terms.
\end{abstract}

Keywords: Child; Childhood; Social construction.

\section{Introdução}

O presente artigo descreve o resultado da pesquisa de iniciação científica PIBIC/PAIC 2020/2021 - PIB-H/0112/2020, intitulada “Construção do conceito infância: uma revisão

\footnotetext{
1 Acadêmica do curso de Licenciatura em Pedagogia, da Universidade Federal do Amazonas (UFAM), e pesquisadora bolsista da Fundação de Amparo à Pesquisa do Estado do Amazonas (FAPEAM), no Programa de Iniciação Científica PIBIC/PAIC 2021/2022 - PIB-H/0043/2021. Integrante do Grupo de Estudos, Pesquisa e Extensão sobre Políticas, Educação, Violências e Instituições (GEPPEvi). Brasil E-mail: vani.ufam @gmail.com. http://lattes.cnpq.br/9191681184155133. ORCID: https://orcid.org/0000-0002-6225-7421.

${ }^{2}$ Doutora e mestre em Educação e mestre em Adolescentes em Conflito com a Lei. Professora permanente do Programa de Pós-Graduação da Universidade Federal do Amazonas (UFAM). Líder do Grupo de Estudos, Pesquisa e Extensão sobre Políticas, Educação, Violências e Instituições (GEPPEvi). Brasil. E-mail: nilvane@ gmail.com. http://lattes.cnpq.br/3429086275125541. ORCID: http://orcid.org/0000-0002-3420-2714.
} 


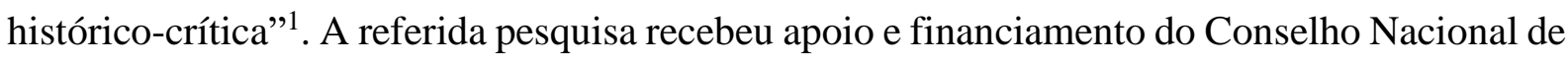
Desenvolvimento Científico e Tecnológico (CNPq).

Almejamos, com este estudo, traçar um percurso histórico a despeito da construção do termo infância e dos significados atrelados a ele, diferenciando o surgimento, no contexto histórico, do termo criança e do termo infância e como esses termos são apresentados nas pesquisas e livros por pesquisadores contemporâneos. Nosso intuito foi compreender por qual motivo o termo se tornou hegemônico e pouco questionado no contexto do capitalismo contemporâneo. O termo infância por vezes se confunde com o termo criança, comumente são tidos até como sinônimos, o que dificulta a compreensão acerca do que, de fato, é ser criança e/ou ter infância na atualidade. Criança é o sujeito concreto, ou seja, todos nós já fomos crianças; infância, por sua vez, é um conceito abstrato, construído socialmente e que se efetivou na modernidade, mas não de forma homogênea em todas as classes sociais, dessa forma, o conceito pode ser diferente, inclusive para crianças de gêneros diferentes pertencentes à mesma família. Não obstante, ambos os termos são associados à classe social de pertencimento, de raça e de etnia.

A partir do resgate histórico, identificamos que as ideias circundantes ao termo infância, mais direcionado ao sentimento de infância, como hoje conhecemos, se consolidou na Idade Moderna $^{2}$ (ARIÈS, 1986). Na intenção de se moldar a noção do que seria esse novo conceito, a infância passou a receber um tratamento específico e diferenciado, inclusive nas atividades laborais, roupas, mobiliários bem como na criação de objetos de consumo (ZANELLA, 2018). Essa compreensão histórica nos despertou o seguinte questionamento: Por qual motivo houve a formulação desse novo termo? Essa e outras questões nos motivaram a iniciar a presente pesquisa bem como nos trouxe a inquietação em conhecer e nos aprofundar sobre o conceito e entender o significado da concepção de infância e as transformações ocorridas ao longo do tempo. Para tanto, estabelecemos como objetivo geral discutir a construção da concepção de infância sob a perspectiva histórico-crítica e como objetivos específicos a) categorizar, no repositório da CAPES, como o termo infância tem sido identificado nas linhas acadêmicas, a partir das principais bibliografias utilizadas; b) identificar as fontes documentais utilizadas nas pesquisas selecionadas; e c) classificar em eixos as pesquisas destacadas.

Partindo do pressuposto de que infância é um conceito historicamente construído e distinto em tempo e lugar, este estudo busca discutir a construção ideológica da concepção de infância a partir da perspectiva histórico-crítica. A análise demanda resposta a seguinte indagação: Quais interesses políticos, econômicos e sociais ligados à formulação do conceito 
de infância tornaram o termo uma construção social hegemônica no sistema capitalista? A fim de respondermos à problematização, acreditamos que seja significativo um levantamento bibliográfico.

Nesse aspecto, o estudo sobre a construção histórica da ideia de infância assume considerável importância, visto que tudo o que acontece, e aconteceu, na sociedade tem relevância em termos acadêmicos e sociais, pois nos permitem vislumbrar possibilidades de transformação, quiçá pensarmos em estratégias de superação.

Desta feita, utilizamos como metodologia a pesquisa bibliográfica e documental de autores referentes ao tema. A pesquisa bibliográfica se debruçou nos estudos sobre infância, de autores como Ariès (1986; 1987), Warde (2007), Klein (2012). A análise documental foi feita nos respectivos locais: Catálogo de Teses e Dissertações da Coordenação de Aperfeiçoamento de Pessoal de Nível Superior $\left(\mathrm{CAPES}^{3}\right)$ e Biblioteca Digital de Teses e Dissertações UFAM $\left(\mathrm{TEDE}^{4}\right)$.

Metodologicamente, a pesquisa bibliográfica foi feita a partir do levantamento de referências teóricas com base principalmente em livros e artigos científicos, os quais já foram previamente analisados e publicados, pois isso nos permitiu conhecer o que outrora já fora estudado acerca das principais teorias que norteiam o problema da pesquisa. Sabemos que, "Embora em quase todos os estudos seja exigido algum tipo de trabalho dessa natureza, há pesquisas desenvolvidas exclusivamente a partir de fontes bibliográficas”, conforme aponta Gil (2002, p. 44).

O método de abordagem deste estudo está baseado na perspectiva histórico-crítica que nos possibilitou investigar as questões sociais e educacionais, pondo em conta suas constantes transformações e contradições na sociedade, bem como compreender os processos sociais que ocorreram ao longo de sua história, comparando as contradições e analisando o todo. Os métodos utilizados caracterizam-se como importantes nas pesquisas em ciências humanas, por serem considerados instrumentos que subsidiam formas de conhecermos, compreendermos e analisarmos o problema da pesquisa sem perdermos de vista a amplitude do tema.

Para responder ao problema de pesquisa, a organização metodológica foi estruturada a partir de análises bibliográficas em fontes diversas e documentais, e demos preferência às fontes primárias. Nesse sentido, cada objetivo específico corresponde a uma seção do artigo e a uma questão problematizadora. 


\section{Inventário das produções acadêmicas a partir do repositório CAPES}

Iniciamos as buscas pelas teses e dissertações no portal da CAPES no ano de 2020, por meio dos seguintes descritores: Infância, Infantil, Historiografia da infância e História da infância. Após anotarmos em uma tabela os descritores pesquisados, observamos que os números retornados dos dois primeiros descritores eram exponenciais, dificultando a análise, em razão dos prazos de entrega dos resultados da pesquisa de iniciação científica. O terceiro não manifestou resultados razoáveis que favorecessem a continuação da pesquisa, todavia o último descritor retornou um quantitativo satisfatório que nos possibilitou realizar a análise das teses e dissertações de pesquisadores que têm contribuído significativamente para compreendermos as trajetórias sociais. Os retornos dos descritores podem ser visualizados no quadro abaixo.

Quadro 1 - Seleção do termo descritor

\begin{tabular}{|c|c|c|c|}
\hline $\mathbf{N}^{\mathbf{0}}$ & DESCRITORES UTILIZADOS & RETORNO & OBSERVAÇÃO \\
\hline 01 & Infância & 13.846 & Sem aspas no termo \\
\hline 02 & Infantil & 20.085 & Sem aspas no termo \\
\hline 03 & "historiografia da infância" & 4 & Termos entre aspas \\
\hline 04 & "história da infância" & 134 & Termos entre aspas \\
\hline
\end{tabular}
Fonte: Elaborado pelas pesquisadoras, $2020^{5}$.

Coletamos o arcabouço teórico no repositório CAPES, utilizando o descritor "história da infância", e recebemos um total de 134 pesquisas, das quais, seguindo os critérios de seleção pré-estabelecidos por nós, a saber, apreciação dos títulos e resumos que confirmassem a aproximação temática bem como a disponibilização das pesquisas completas para leitura, selecionamos o total de 41 pesquisas para análise, sendo 12 pesquisas de doutorado e 29 de mestrado, conforme demonstramos no quadro abaixo.

Quadro 2 - Organização das pesquisas selecionadas quanto às fontes de origem

\begin{tabular}{|c|c|c|}
\hline PRODUÇÃO & $\begin{array}{c}\mathrm{N}^{\circ} \mathrm{DE} \\
\text { PESQUISAS }\end{array}$ & AUTORES \\
\hline Mestrado & 29 & $\begin{array}{l}\text { Silva (2003); Oliveira (2005); Azevedo (2006); Zaniani } \\
\text { (2008); Duarte (2008); Sousa (2009); Miceli (2010); } \\
\text { Oliveira (2010); Miranda (2010); Pessoa (2010); Carneiro } \\
\text { (2011); Cezário (2012); Silva (2012); Bernhard (2013); } \\
\text { Pinto (2013); Pinheiro (2013); Borges (2013); Camargo } \\
\text { (2014); Reis (2014); Lanna (2016); Santos (2017); Silva } \\
\text { (2017); Frias (2017); Lima (2017); Gualberto (2017); } \\
\text { Correa (2017); Oliveira (2018); Silva (2019); Weinhardt } \\
\text { (2019). }\end{array}$ \\
\hline
\end{tabular}




\begin{tabular}{|l|l|l|}
\hline \multirow{3}{*}{ Doutorado } & \multirow{2}{*}{12} & $\begin{array}{l}\text { Nogueira (2010); Molina (2011); Gomes (2012); Conceição } \\
\text { (2014); Anjos (2015); Cordeiro (2015); Lima (2015); Grotti } \\
\text { (2016); Santos (2017); Mota (2017); Pacheco (2017); } \\
\text { Ribeiro (2018). }\end{array}$ \\
\hline
\end{tabular}

Fonte: Elaborado pelas pesquisadoras, $2021^{6}$.

O quadro acima marca o recorte de tempo datado dos anos de 2003 a 2019, sendo 2017 o ano com mais pesquisas defendidas: seis dissertações e três teses. Em ordem decrescente, destacamos, ainda, que foram defendidas cinco pesquisas em 2010, sendo quatro dissertações e uma tese. Em 2013, apresentam-se quatro trabalhos, com prevalência nas pesquisas de mestrado; já em 2012, contabilizamos três trabalhos, sendo duas dissertações e uma tese. Referente aos anos de 2014 e 2015, temos três pesquisas em cada ano, em um equilíbrio de duas dissertações e uma tese, no ano de 2014, e três teses defendidas em 2015. Relativo aos anos de 2008, 2011, 2016, 2018 e 2019, cada um apresentou duas pesquisas e, em 2003, 2005, 2006 e 2009, obtivemos apenas uma pesquisa em cada ano, sendo, exclusivamente, dissertações.

As pesquisas que contribuem na composição deste estudo enquadram-se na grande área de ciências humanas, com prevalência no campo da educação, em que contabilizamos 28 pesquisas, como podemos verificar no gráfico abaixo.

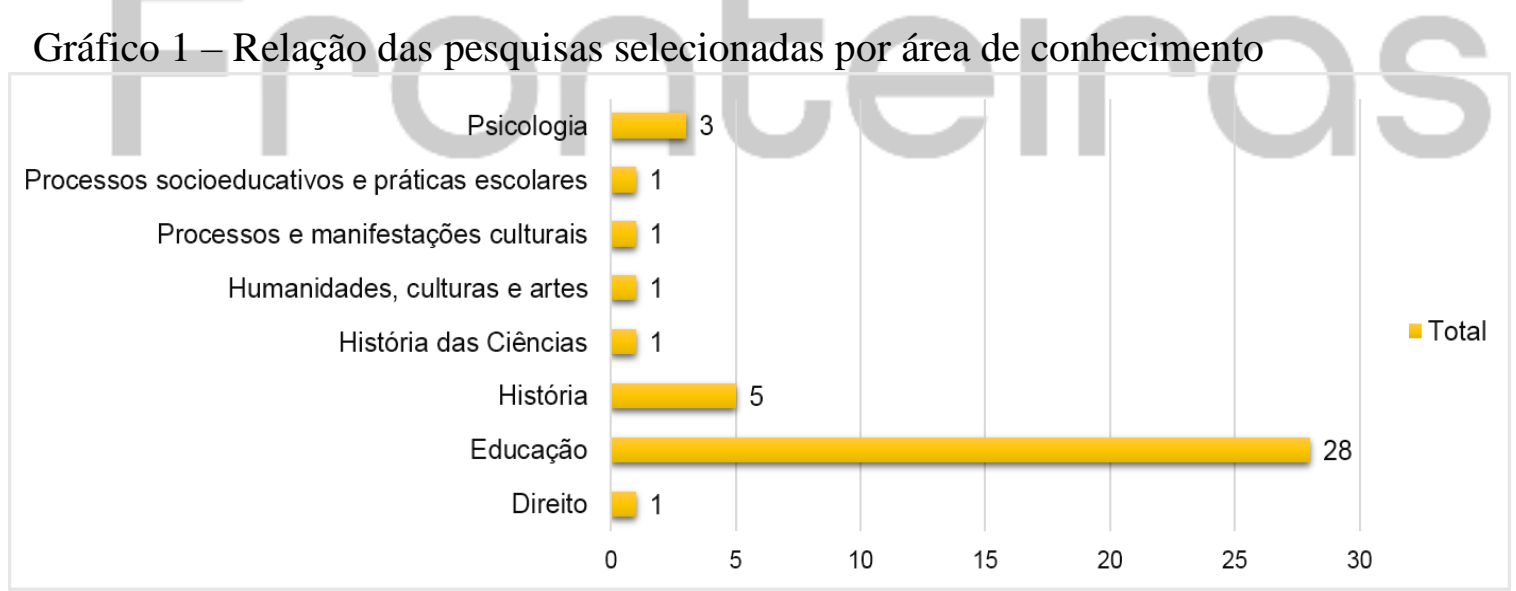

Fonte: Elaborado pelas pesquisadoras, $2021 .^{7}$

Destacam-se, ainda, cinco pesquisas na área de história e três pesquisas na área da psicologia. As demais áreas, contabilizaram uma pesquisa cada.

\section{A presença do tema infância nas pesquisas recolhidas no repositório CAPES: a descrição dos trabalhos selecionados}

Após a leitura dos títulos e resumos, agrupamos as pesquisas em 12 eixos temáticos, de modo a viabilizarmos a leitura e análise dos trabalhos selecionados. Elencamos, assim, os estudos baseados no tema central proposto. 
Quadro 3 - Organização das pesquisas selecionadas por eixos temáticos

\begin{tabular}{|c|c|c|c|c|}
\hline $\mathbf{N}^{\mathbf{0}}$ & EIXO TEMÁTICO & TESES & DISSERTAÇÕES & TOTAL \\
\hline 01 & Assistência à infância & 01 & 01 & 02 \\
\hline 02 & Cultura da infância & 02 & 02 & 04 \\
\hline 03 & $\begin{array}{c}\text { Direitos da criança e do } \\
\text { adolescente }\end{array}$ & 01 & 01 & 02 \\
\hline 04 & Educação familiar & 01 & 02 & 03 \\
\hline 05 & Educação para infância & 02 & 04 & 06 \\
\hline 06 & Higienismo & 00 & 01 & 01 \\
\hline 07 & História da infância & 03 & 06 & 09 \\
\hline 08 & Infância desvalida & 00 & 04 & 04 \\
\hline 09 & Infância institucionalizada & 01 & 04 & 05 \\
\hline 10 & Menores & 00 & 02 & 02 \\
\hline 11 & Revisão literária & 01 & 01 & 02 \\
\hline 12 & Trabalho infantil & 00 & 01 & 41 \\
\hline TT & - & 12 & 29 & \\
\hline
\end{tabular}

Fonte: Elaborado pelas pesquisadoras, $2021 .^{8}$

Em prosseguimento, inferimos um tratamento mais específico por meio de uma revisão bibliográfica às pesquisas antepostas e tecemos considerações referentes ao objetivo geral, destacando, assim, os principais teóricos e campos de estudo que têm contribuído cientificamente no embasamento de novas pesquisas acerca do tema infância e criança como termos construídos socialmente.

Ressaltamos que os dados coletados subsidiaram uma pesquisa de iniciação científica. Logo, destacamos sinteticamente as ideias principais de cada pesquisa, de maneira a conhecermos o que tem sido produzido sobre o tema no Brasil.

\section{Assistência à infância}

Os trabalhos desse eixo caminham em direção à mesma temática, porém em vieses diferentes. A pesquisa de Grotti (2016) aborda o tema na perspectiva de conhecer e analisar a historização da assistência à criança pobre em Rio Branco (AC), a partir da veiculação do denominado problema da infância ${ }^{9}$ repercutido nos periódicos, em especial, no jornal O Acre, nos anos de 1940. A tese discorre que, mediante um ideal republicano de modernização da nação, as crianças passaram a ser vistas como "[...] a base da constituição da sociedade brasileira" (GROTTI, 2016, p. 20). Nesse contexto, a autora destaca o surgimento de ações assistencialistas ${ }^{10}$ apoiadas em projetos e representações de outras partes do país, visando fortalecer o território estadual, conforme suas particularidades. 
Por sua vez, Santos (2017) apresenta uma pesquisa do tipo levantamento bibliográfico, em que buscou analisar as publicações nos anais do Congresso Brasileiro de História da Educação (CBHE), das edições de 2000-2015. A pesquisadora demonstra a recorrência de estudos realizados no âmbito da pesquisa acadêmica referente ao tema bem como a apresentação no CBHE e comprovou que o tema esteve presente em todas as edições do congresso, sempre relacionado ao campo da história da educação, todavia há prevalência de estudos que investigam as instituições de assistência e a assistência destinada à infância (entre elas, a escola) e que indicam que a educação da infância pobre era no sentido da moralização e higienismo mental e corporal.

Uma característica que predomina em ambas as pesquisas é voltada às conclusões dos estudos que indicam que um dos meios de assistência à infância é a educação, pois se visava que as crianças se tornassem úteis ao progresso da nação, ascendendo o país à modernidade.

\section{Cultura da infância}

Este eixo discorre sobre a concepção de infância veiculada em mídias cinematográficas, nos vestuários criados para as crianças e nas relações vivenciadas entre estas e os adultos na sociedade. A vista disso, Santos (2017) foca sua pesquisa em analisar o discurso disseminado em três produções do cinema brasileiro que têm o protagonismo de crianças, contrapondo à concepção social instituída sobre infância e as práticas culturais das crianças.

No mesmo viés, Pinto (2013) e Gomes (2012) observam e analisam as relações intergeracionais e com seus pares. Os estudos apontam que a cultura infantil tende a ser, em muitos aspectos, uma reprodução da cultura adulta, em razão do processo de adultocentrismo característico das relações familiares e comunitárias, e que, a partir da participação, atuação e socialização entre os pares e os demais indivíduos, acontece uma reestruturação social que acarretará na construção do fenômeno da infância, produzindo, assim, novos sentidos e valores no ser infantil.

Em um campo diferenciado, Bernhard (2013) centraliza seus estudos em entender a relação entre a representação social da infância e as roupas desenvolvidas para essa fase da vida e afirma que o vestuário infantil é reflexo da contradição entre a adultização e o conhecimento produzido ao longo dos séculos (IV-XXI) sobre a importância de a criança vivenciar a infância em sua plenitude.

Os estudos analisados neste eixo mostram que as temáticas referendadas versam sobre as produções culturais desenvolvidas para as crianças, com pouca ou nenhuma contribuição 
delas, porém reafirmam que a participação ativa das ações culturais desenvolvidas pelas crianças constitui-se em peça angular na construção social da concepção da infância contemporânea.

\section{Direitos da criança e do adolescente}

A pesquisa de Nogueira (2010) se propôs a discutir o papel do Estado na garantia e manutenção dos direitos da criança e do adolescente. Para isso, a pesquisadora buscou arcabouço documental na Constituição Federal de 1988, no Estatuto da Criança e do Adolescente - ECA - e na Lei de Diretrizes e Bases da Educação Nacional - LDB, a despeito dos direitos específicos do público em questão, porém a autora deixou claro que não realizou nenhum tipo de recorte social e que sua análise abrangeu a categoria infância e adolescência em um contexto geral, já que a lei não especifica as classes sociais de origem deles.

Todavia, outra leitura das bases legais sobre os direitos da criança e do adolescente é realizada por Miceli (2010, p. 430); a autora afirma que “[...] o estatuto social das crianças foi pensado e regulado com base num conjunto de interdições e prescrições que lhes nega poderes e capacidades e as considera incompetentes [...] a lei retrata a infância com base em ideais, e não a partir de crianças reais, como sujeitos de suas histórias". Logo, ela considera indispensável uma educação em direitos, sobretudo no espaço escolar, para dar subsídios à autonomia de crianças e adolescentes em desenvolvimento, enquanto sujeitos constituídos de conhecimentos e competências, a fim de promover a liberdade do "direito de ser", dando visibilidade a esses sujeitos, de modo que a sociedade e o Estado venham a se comprometer de fato com as causas destes.

\section{Educação familiar}

O eixo dispõe de três pesquisas que buscam compreender como se dava o processo de educação das crianças dentro do ambiente familiar. Elas marcam um recorte de tempo de meados finais do século XIX às décadas do início do século XX. Nesse foco, Anjos (2015) e Carneiro (2011) buscaram desvelar o entendimento sobre o que caracterizava a educação das crianças conforme a representação das práticas institucionais e familiares. As pesquisas mostraram que, a fim de atender ao discurso dos projetos republicanos, a educação ofertada no âmbito familiar era consoante ao modelo do adulto que se almejava para o futuro. Assim, as crianças que não se encaixavam nesse padrão eram punidas, para que entendessem o "seu lugar" na família e na sociedade. Nessa mesma perspectiva, caminha a pesquisa de Sousa (2009) que 
analisou as permanências e as transformações referentes à educação das infâncias investigadas a partir de três temáticas, o trabalho, a escola e o divertimento. O estudo concluiu que, nas duas primeiras gerações, o trabalho se caracterizou como objeto educacional na formação dos indivíduos, ao passo que, na terceira geração, considerou-se a escola a principal instituição de referência na educação.

As análises realizadas neste eixo mostraram que a educação no ambiente familiar sempre foi voltada às representações vividas pelas gerações anteriores e pautadas no modelo de sociedade que o Estado previa. No entanto, algumas transformações foram observadas, porém todas no sentido da elaboração de um novo significado aos elementos perpetuados na relação intergeracional.

\section{Educação para a infância}

Este eixo ressalta a forma como as políticas públicas do campo educacional conceituam a infância e, a partir dessa concepção, efetuam suas práticas, mediante os aparatos legais. Dessa forma, Miranda (2010) fundamenta seu aporte teórico em uma pesquisa histórica e documental a fim de mostrar dados que comprovam a presença de crianças negras no processo educacional público de Cuiabá entre os anos de 1870 a 1890. O estudo de Miranda (2010,p. 70) apontou a "[...] presença de alunos negros e até escravos em Cuiabá que frequentavam as escolas públicas" no período anterior à abolição da escravatura. Após esse período, verificou-se a oferta de ensino moralista e com ênfase no trabalho, pois " [...] necessário era educá-los, pois não tinham 'os princípios de moral e religião, eivados dos vícios de cativeiro e no mais completo obscurantismo"” (MIRANDA, 2010, p. 71).

Apesar do fato de que as crianças negras estavam ocupando esses espaços, mesmo que ainda timidamente, Miranda (2010, p. 71) afirma que isso "não significa que a educação era realmente para todos e, muito menos, que o preconceito estava ausente nas relações cotidianas escolares".

Olhando para um tempo não muito distante deste, as pesquisas de Oliveira (2018) e Silva (2019) realizam uma imersão na história da infância brasileira a partir dos anos de 1990 a 1905 e 1937 a 1962, respectivamente. Os estudos demonstraram que a educação escolar tinha uma carga moralizadora, com vistas a formar cidadãos contribuintes na modernização do Brasil, conforme os ideais políticos da época. Em um viés amplo, Conceição (2014) marca como recorte de tempo os anos de 1980 a 1990, inferindo que as políticas públicas educacionais surgiram em um sentido compensatório e assistencial, direcionado, sobretudo, às crianças 
pobres e sobrepondo essa dimensão social em detrimento de todas as outras que constituem uma pessoa. Essa autora afirma que, nessa dimensão de criança pobre, carente e consequentemente submissa, é indispensável a institucionalização dela, a fim de receberem o direcionamento social por meio de uma política nacional conformadora de corpos.

Os estudos de Oliveira (2010) e Mota (2017) mostraram que a concepção de infância dessas políticas é marcada pela limitação do "vir a ser"11, que considera a infância o "[...] período de desenvolvimento e aprendizagem, tendo como foco a preparação para o estágio posterior" (MOTA, 2017, p. 8). Esse fato tende a invisibilizar a criança concreta e cidadã no tempo real.

Compreendemos que, apesar de as pesquisas deste eixo terem recortes de tempo diferentes, as concepções de infância ainda se fazem presentes e com poucas novas estruturações. Os discursos das políticas de atendimento educacional se mostravam atentas à valorização da infância, mas o que se via na prática era a invisibilidade infantil, que negava as suas particularidades, “[...] isolando-a como elemento único da relação pedagógica e deslocando suas raízes históricas, culturais e sociais" (SILVA, 2019, p. 11), caracterizando a infância como sinônimo da fase cronológica e biológica da criança e que por isso esta necessitava ser sempre direcionada pelo adulto para futuramente se tornar um ser partícipe na sociedade e atender aos interesses do Estado.

\section{Higienismo}

Zaniani (2008) se propôs a estudar a concepção de proteção à infância apregoada por Morcovo Filho, situando-a no tempo e na sociedade que a engendrou (1899 a 1938). Conforme a pesquisadora, Morcovo Filho compartilhava dos ideais nacionalistas de cunho higienista ${ }^{12}$ que considerava que a construção da sociedade moderna se efetivaria com a proteção à infância, pois “[...] as mazelas sociais que se multiplicavam não rimavam com os modelos civilizados de nação e não cooperavam com as exigências da nova ordem burguesa, que buscava se consolidar" (ZANIANI, 2008, p. 12). A pesquisa apontou que Morcovo Filho contribuiu na criação de novos aparatos em prol da proteção à infância, e, a exemplo disso, destacam-se as creches e as maternidades.

Porém, o estudo conclui que os pressupostos ideológicos que direcionaram essas ações protetivas à infância arrolavam no sentido de proteção da sociedade contra os "problemas da infância", distinguindo uma infância que necessitava de proteção e outra que deveria ser corrigida em vista de criar uma nação forte, livre dos males sociais hereditários. Todavia, 
Zaniani (2008) infere que os males sociais não podem ser dissipados sem uma reestruturação econômico-social.

\section{História da infância}

Lima (2015) interrelacionou os contextos histórico, sociopolítico, econômico, cultural e educacional dos anos de 1897 a 1920 a duas obras literárias e procurou tecer reflexões sobre as representações da infância amazônica discursadas nas linhas dessas obras. A pesquisadora ressalta as infâncias antagônicas relatadas nessas obras: uma representa a infância vivida economicamente confortável em que o importante era se aprender os valores sociais e morais para se ser inserido na sociedade, a outra representa uma infância vivida por seus sujeitos que, de alguma forma, reconhecem sua situação de opressão e miséria econômica, mas que encontram forças para fugir dela por meio da imaginação, mostrando, assim, uma vontade de romper com as questões sociais em que estão inseridos.

Nesse mesmo viés de compreensão, Ribeiro (2018) sustenta a tese de que a história da infância se revela entre a dicotomia marcada pela barbárie e pelo encantamento do mundo. Ele afirma que, ante essas discrepâncias das múltiplas infâncias, a criança vive em

Busca de um lugar verdadeiro de proteção e protagonismo, porque as promessas que lhes foram feitas se realizam, na maioria das vezes, enquanto promessas-barbárie. As promessas societárias hegemônicas de hoje e de ontem para a infância pobre são projetos civilizatórios que pouco mais fazem do que manter o consenso social e o devido lugar 'marginal' estruturalmente 'destinado' a determinados grupos sociais pelo projeto capitalista burguês moderno (RIBEIRO, 2018, p. 21-22).

Porém, como se conseguir um protagonismo infantil diante da invisibilidade das crianças? Como lhes assegurar um lugar de fala, sobretudo às classes sociais mais baixas? Questionamentos como esses levaram Camargo (2014) a aprofundar-se a respeito das vozes das crianças, entendendo que estas são seres pensantes, que se expressam por múltiplas linguagens e não apenas reproduzem a cultura do seu meio, mas também contribuem na sua produção. Ante esse entendimento, Camargo (2014, p. 81) expressa que “[...] escutar suas vozes é escutar o que muitas vezes não conseguimos entender, pois suas vozes denunciam, interrogam, expressam e exteriorizam histórias reais, histórias inventadas, histórias das sociedades e das culturas". Evidencia-se, assim, que as crianças não são seres estáticos e que não estão aquém das questões sociais vividas por elas, na verdade, elas estão sendo silenciadas ou moldadas dentro de uma concepção adultocêntrica de como devem ser as suas infâncias. 
Nessa concepção, Duarte (2008) exaltou as vozes de seus entrevistados, pessoas que, acima dos 80 anos de idade, contribuíram no campo científico por meio da exposição de suas memórias da época de criança. O pesquisador informou, ao seu leitor, que buscou dar voz e vez aos seus colaboradores que "[...] representaram a história de muitas crianças que tiveram sonhos e fantasias em uma época marcada pela infância negada" (DUARTE, 2008, p. 121). Mediante essa compreensão, Cezário (2012) contribui dizendo que, quanto mais entendermos a infância, maior será nossa compreensão sobre o homem, suas relações e suas experiências que vivem em constantes mudanças, haja vista nossa incompletude humana.

Na mesma direção se encaminha a dissertação de Lanna (2016); esta buscou ouvir as vozes de crianças e as percepções destas sobre o que pensam ser a infância, como sobrevivem nesse construto social e como suas relações interferem na sua socialização e educação, logo, o seu processo de humanização. Ao realizar esse processo, a pesquisadora objetivava analisar os discursos socio-históricos produzidos sobre a infância e detectou que os discursos são reproduzidos conforme as lentes são usadas para se ver, assim, segundo a concepção teórica, novas formulações são produzidas, afirmando a multiplicidade de experiências e expectativas vividas pelas crianças, as que quase denominamos infância.

Lançando mão de outra metodologia, mas sem perder de foco a história da infância, a pesquisa de Pinheiro (2013) analisou os discursos sobre a infância paraense da primeira década do século XX, os quais eram difundidos nos jornais Folha do Norte e A Província do Pará. O pesquisador contextualizou suas descobertas no advento da república que trouxe, consigo, as "medidas de proteção à infância". Destrinchou cada notícia, anúncios, propagandas, galerias de fotos que se referiam às crianças e concluiu que os discursos eram carregados de uma ideologia dominante e classicista. Ele inferiu que,

No caso da criança pobre, notou-se que esta era sempre tratada como um sujeito que estava "jogado a própria sorte", sem perspectivas de um futuro, tendo em vista que ela sempre vai ser tida como a criança 'desafortunada', a 'infeliz', 'a pobre creança'; já a da classe economicamente mais favorecida é sempre a bela, formosa, a ingênua, a bem cuidada e aquelas que terão um futuro promissor, inclusive pelo fato de seus pais terem sido pessoas de sucesso e, por isso, simbolicamente lhes é dado a oportunidade de receber tal legado (PINHEIRO, 2013, p. 135-136).

Ao observarmos esses discursos, vemos que essa realidade não se distancia da realidade do século XXI, em que vemos perpetuar as falas das classes dominantes, as quais se impõem sobre as demais, menosprezando as culturas das minorias. Nesse ínterim, a pesquisa de Santana (2014) traz à baila a análise da infância a partir da observação dos brinquedos, em evidência à 
boneca Barbie e à boneca Karajá-Ritxòkò ${ }^{13}$ como produtos culturais na construção da identidade das meninas indígenas da aldeia Buritina. A pesquisa mostrou que

Os brinquedos estão imersos nas relações de poder, apresentando discursos implícitos à sua materialidade do que é bom, bonito, normal, atraente, verdadeiro e prazeroso para a cultura hegemônica e capitalista [...] ressalta-se que em uma sociedade capitalista e consumista, preparada para a produção e consumo em ritmo frenético, os brinquedos artesanais sofrem discriminação (SANTANA, 2014, p. 147-148).

Todavia, a pesquisadora reforça a importância dos brinquedos nas atividades lúdicas das crianças e no fortalecimento da interculturalidade. Ante o exposto, entendemos que uma das formas de ampliarmos o conhecimento sobre a historiografia da infância e debatermos o tema cientificamente, de modo que isso perpetue e promova novas reflexões, é mediante a publicação dos trabalhos produzidos academicamente, em que os pesquisadores expõem suas teses, impressões e inquietações acerca das diversas temáticas sociais. Nesse sentido, Cordeiro (2015) preocupou-se em analisar os debates sobre questões referentes à infância na América. Para isso, aprofundou sua pesquisa a partir do estudo dos três primeiros Congressos Americanos del Niño, para conhecer e entender as representações da infância debatida nesses espaços de apropriação e divulgação científica.

\section{Infância desvalida}

A temática discorre acerca das crianças órfãs e abandonadas e, consequentemente, dos abrigos destinados a elas, fossem institucionais, fossem residenciais, onde as novas famílias, consanguíneas ou não, as recebiam. Frias (2017) tratou de observar detalhes relacionados à idade limite da infância nos anos de 1823 a 1831. Para os meninos, esse limite acabava aos 15 anos e, para as meninas, aos 12 anos e meio, conforme sua inserção no mundo do trabalho ou do matrimônio. Referente à formação recebida, constatou-se discrepância conforme o gênero, idade e situação econômica - os meninos tinham mais acesso à cultura escrita e possibilidade de alçar estágios superiores, já as meninas tinham acesso elementares à cultura escrita e de leitura, e a formação tinha um direcionamento às prendas domésticas.

Na mesma lógica, os estudos de Azevedo (2006) e Silva (2017) destacaram um viés religioso cristão (espírita e católico), respectivamente, sobre a questão dos abrigos para a infância desvalida, a partir de considerações relacionadas à caridade mediante a fé como símbolo para acolher os órfãos e abandonados. Por outro lado, Silva (2003) direcionou sua pesquisa em mostrar como se deu o processo de cuidado aos abandonados e "delinquentes" 
pelo Laboratório de Biologia Infantil (LBI), que surgiu em 1937, com a função de identificar o que causava a criminalidade infantil praticada por essas crianças. A pesquisa mostrou que o laboratório utilizou a repressão e a assistência como métodos para cuidar da infância abandonada na década de 1930 e que as marcas desse processo ainda podem ser encontradas no Brasil do século XXI.

\section{Infância institucionalizada}

Mediante pesquisa documental e entrevistas orais, Pacheco (2017) evidenciou a história e experiências educativas de crianças que foram afastadas do convívio de seus pais que haviam contraído hanseníase na primeira metade do século XX, no Brasil, sendo institucionalizadas em preventórios/educandários, conforme prescrevia a política pública de isolamento compulsório. A tese revelou que essas crianças vivenciaram suas infâncias, isoladas de suas famílias e da sociedade, por meio do controle de seus corpos com disciplina e violências físicas e psicológicas.

Nesse seguimento, Lima (2017) buscou compreender como se dava a assistência prestada pela Casa do Pequeno Jornaleiro (CAPEJO), entre os anos de 1960 a 1978, à criança "abandonada" e constatou que a instituição se diferenciava das demais, pois nem era direcionada ao ensino regular e religioso e ao trabalho moralizador a partir da venda de jornal. A pesquisa mostrou que grande parte dos meninos institucionalizados nessa instituição tinham famílias e não eram de fato abandonados ${ }^{14}$.

Poletto (2013) realizou uma leitura crítica sobre as instituições de acolhimento, apontando uma desarticulação nas políticas públicas que corroboram as institucionalizações, esse fato levou a pesquisadora a concluir que pouco adianta institucionalizar as crianças se as famílias destas não fizerem parte do processo, logo, o ciclo de violências se perpetuará. Nesse sentido, Oliveira (2005) destaca que os resquícios das desigualdades promovem a violência a esse público na contemporaneidade brasileira.

Nessa propositura, Gualberto (2017) valorizou as vozes das crianças de cinco a 12 anos que vivem em acolhimento institucional. Dessa forma, a pesquisadora mostrou uma nova forma de se pesquisar a institucionalização infantil, a partir da escuta das experiências delas, colocando a centralidade no sujeito e não apenas no processo ou na instituição.

\section{Menores}


Os estudos nesse eixo perfazem o recorte de tempo do final do século XIX e início do século XX, período marcado por uma mudança política e econômica no Brasil. E é nesse contexto de transformações sociais que os pesquisadores Weinhardt (2019) e Corrêa (2017) discutem a respeito dos discursos e práticas voltadas às crianças e adolescentes marginalizados. A pesquisa de Weinhardt (2019) descreve que as crianças e jovens pobres eram transmudados em menores, marca de uma correlação sinônima entre a pobreza e a criminalidade.

Acerca da transição política, Corrêa (2017, p. 170; 172) discorre que

[...] o pensamento da elite, intelectual e política da sociedade, girou em torno de uma proposta patriótica de construção e modernização nacional segundo modelos internacionais de sociedade [...] e nesse entretempo, as crianças foram sendo entrepostas numa rotina de 'modelo de civilidade' que lhes custou: a liberdade e os direitos como cidadãos.

Percebemos que a história das crianças e adolescentes no Brasil carrega características de um tempo de transição de ordens política, econômica e social, que só recebeu olhares das autoridades segundo as intenções do progresso nacional, mas que de fato enxergava a infância pobre como um "problema" a ser solucionado.

\section{Revisão literária}

Dispondo metodologicamente de uma pesquisa documental, Molina (2011) analisou as dissertações e teses produzidas nos Programas de Pós-Graduação em Educação do país, enquanto Silva (2012) se dispôs a analisar 24 artigos publicados pela Revista Brasileira de Educação (RBE).

Silva (2012) afirmou que a temática da infância tem sido inter-relacionada à história da infância, e seu elo tem sido a educação. Destacou que as interpretações dos discursos veiculados nos artigos dependem de quem o ler, haja vista a dinamicidade textual e as construções de sentido empregado por cada leitor. Em consonância, Molina (2011) destacou que, conforme o aporte teórico-metodológico, surgem os diferentes conceitos sobre o objeto pesquisado. Inferiu ainda que a aproximação entre as áreas do conhecimento é o que possibilita se estudar um objeto em diferentes perspectivas.

\section{Trabalho infantil}

O eixo conta com um estudo direcionado às dimensões do trabalho infantil na cidade de Manaus, no decurso do tempo conhecido como "Belle Époque", período de transformação econômica, mas também de hábitos sociais. Foi nesse contexto que Pessoa (2010) buscou 
revelar o espaço social que as crianças ocupavam referente ao mundo do trabalho e identificou que o trabalho infantil esteve presente no tempo e espaço pesquisado; constatou ainda que as famílias questionavam as condições de trabalho a que seus filhos eram impostos, mas não ao trabalho em si. A pesquisadora detectou que a preparação dessa mão de obra se constituía mediante as instituições educacionais que prestavam assistência às famílias pobres e ao ensino de um ofício.

\section{As fontes documentais utilizadas nas pesquisas selecionadas}

Para realizarmos a análise quantitativa e descritiva desse processo, valemo-nos inicialmente dos agrupamentos outrora utilizados para descrevermos as 41 pesquisas selecionadas. Desta feita, copiamos as referências de todas as pesquisas organizadas nas pastas dos 12 eixos temáticos, em seguida, colamos em um documento Word, classificamos em ordem alfabética e as enumeramos. Dessa forma, pudemos observar, registrar e expor, no quadro, os autores mais usados em cada eixo.

O quadro abaixo apresenta os referenciais teóricos mais recorrentes concomitantes aos 12 eixos temáticos bem como o total das recorrências e das referências analisadas. Vale ressaltarmos que não excluímos as repetições nem referentes ao autor e nem à sua obra, pois nosso objetivo é analisar os referenciais teóricos que compõem os eixos temáticos.

Quadro 4 - Organização dos aportes teóricos

\begin{tabular}{|c|c|c|c|c|}
\hline $\mathbf{N}^{\mathbf{0}}$ & EIXO TEMÁTICO & $\begin{array}{l}\text { REFERENCIAL } \\
\text { TEÓRICO } \\
\end{array}$ & TT & $\begin{array}{c}\text { REFERENCIAS } \\
\text { ANALISADAS (TT) }\end{array}$ \\
\hline 01 & Assistência à infância & KUHLMANN Jr., Moysés & 07 & 271 \\
\hline 02 & Cultura da infância & QVORTRUP, Jeans & 19 & 546 \\
\hline 03 & $\begin{array}{c}\text { Direitos da } \\
\text { criança/adolescente }\end{array}$ & FREIRE, Paulo & 07 & 163 \\
\hline 04 & Educação familiar & CHARTIER, Roger & 14 & 505 \\
\hline 05 & Educação para infância & KUHLMANN Jr., Moysés & 19 & 982 \\
\hline 06 & Higienismo & MONCORVO FILHO, A. & 17 & 119 \\
\hline 07 & História da infância & BENJAMIM, Walter & 34 & 976 \\
\hline 08 & Infância desvalida & KARDEC, Allan & 11 & 278 \\
\hline 09 & $\begin{array}{c}\text { Infância } \\
\text { institucionalizada }\end{array}$ & RIZZINE, Irene & 18 & 602 \\
\hline 10 & Menores & RIZZINE, Irene & 06 & 301 \\
\hline 11 & Revisão literária & MARX, Karl & 06 & 208 \\
\hline 12 & Trabalho infantil & $\begin{array}{l}\text { PINHEIRO, Maria Luiza } \\
\text { Ugarte }\end{array}$ & 04 & 84 \\
\hline TT & - & - & - & 5.035 \\
\hline
\end{tabular}

Fonte: Elaborado pelas pesquisadoras, $2021 .{ }^{15}$ 
Destacamos, ainda, a prevalência de alguns autores clássicos no campo da infância e história da infância, os quais estiveram presentes em mais de 50\% do referencial teórico analisado por eixos, a saber, Philippe Ariès, presente em nove eixos. O autor é amplamente referenciado por ser considerado o historiador a inaugurar uma nova concepção de investigação historiográfica na qual inseriu as crianças e a infância, discutindo as peculiaridades delas (SANTANA, 2014).

Como forma de manter a dialeticidade nas pesquisas, observamos que os pesquisadores recorreram às teses de autores brasileiros para elaborarem o panorama das múltiplas questões referentes à infância no Brasil. Entre eles, se destacam Moysés Kuhlmann Jr., citado em sete eixos, e Mary Del Priore, em seis eixos. A maior incidência das contribuições de Kuhlmann Jr. encontra-se nos eixos educação para infância e história da infância, contabilizando 19 aparições em cada eixo. Referente à maior recorrência dos estudos de Del Priore, destaca-se o eixo história da infância. Subentendemos que os pesquisadores brasileiros têm recorrido às obras nacionais ao fundamentarem seus estudos científicos a despeito do objeto de análise desta pesquisa, o que mostra uma centralidade em se entender as particularidades da criança concreta e as suas vivências infantis na nossa sociedade, seja em um viés nacional ou em um regional.

\section{Considerações finais}

A partir das análises realizadas nas 41 pesquisas selecionadas no repositório de dissertações e teses da CAPES, é possível apresentarmos alguns apontamentos.

A prevalência das pesquisas analisadas sobre a infância e história da infância tem sido objeto das dissertações de mestrado, decorrentes entre os anos de 2003-2019, sendo a Universidade Federal do Pará a instituição com o maior número de pesquisas defendidas. Todavia, a região do país que mais tem produzido pesquisa sobre o tema é a região Sul, e destacamos a inexistência de pesquisa defendida na região Nordeste. Ressaltamos que a área com o maior índice de pesquisa tem sido nos Programas de Pós-Graduação em Educação, o que revela o fato de a criança ainda ser considerada objeto quase que exclusivo de estudo nessa área. Todavia, ressaltamos que cinco pesquisas são da área de história, o que mostra que os estudos sobre a criança e a infância têm conquistado, ainda que timidamente, novos campos de pesquisa, inclusive alguns estudos estavam atrelados aos campos da sociologia e antropologia.

Mediante a leitura e inferições das pesquisas selecionadas, as quais foram agrupadas em 12 eixos temáticos e analisadas uma a uma, vimos que os pesquisadores contemporâneos têm 
se ocupado de visitar o passado para entenderem as transformações em torno da criança e da infância. Observamos uma quase unanimidade em pesquisas que se reportam às transformações políticas e econômicas advindas da passagem do século XIX ao século XX, para explicarem a construção da concepção de criança e infância no Brasil. Dessa forma, entendemos que muitas foram as situações que moldaram a percepção sobre o ser infantil. Destacamos, principalmente, a distinção entre uma infância que necessitava de proteção e outra que deveria ser corrigida, pois o ideal da época era a formação de uma nação forte, subjugadora das "mazelas" sociais. Nessa concepção, as crianças pobres foram tidas como "problema" social que deveria ser resolvido. Assim, foram criadas as políticas de higienismo, cunhadas sob o pretexto de políticas de proteção à infância, que institucionalizaram crianças e afirmaram a necessidade dessa ação ao usarem a pobreza como sinônimo de delinquência. Por outro lado, as crianças abastadas eram retratadas como o futuro da ordem e do progresso nacional. A similaridade percebida ao tratamento das crianças é referente à educação marcada pela moralização social, com vistas a formar cidadãos contribuintes na modernização do Brasil, conforme os ideais políticos da época. É certo que, no Brasil do século XXI, as marcas desse processo ainda podem ser encontradas.

Cientes da importância e urgência em se fazer ciência nesse país, esperamos que esta pesquisa possa contribuir academicamente com os estudos sobre a infância, possibilitando o rompimento da visão reducionista que iguala a perspectiva abstrata de infância à concretude da criança e que nega as muitas infâncias vividas na sociedade contemporânea.

\section{Referências bibliográficas}

ANJOS, Juarez José Tuchinski. Pais e filhos na província do Paraná: Uma história da educação da criança pela família. 2015, 617 f. Tese (Doutorado em Educação) - Universidade Federal de Paraná, Curitiba, 2015.

ARIÈS, Philippe. El nino y la vida familiar en el Antigo Regime. Madrid: Taurus, 1987.

ARIÈS, Philippe. História social da criança e da Família. 2. ed. Rio de Janeiro: Guanabara, 1986.

AZEVEDO, Alexandre Ramos de. Abrigos para a infância no Brasil: por que, quando e como os espíritas entraram nessa história?. 2006. 177 f. Dissertação (Mestrado em Educação) - Faculdade de Educação, Universidade do Estado do Rio de Janeiro, Rio de Janeiro, 2006.

BARROS, Maria Mercedes Ribeiro de. Metáforas da perda da inocência. 2005, $152 \mathrm{f}$. Dissertação (Mestrado em LETRAS) - Universidade do Estado do Rio de Janeiro, Rio de Janeiro, 2005. 
BDTD. Biblioteca Digital de Teses e Dissertações. Disponível em: https://tede.ufam.edu.br/. Acesso em: 29 jan. 2021.

BERNHARD, Júlia Cristina Valim. A representação social da infância e suas influências na moda. 2013, 229 f. Dissertação (Mestrado em Processos e Manifestações Culturais) FEEVALE, Novo Hamburgo, Rio Grande do Sul, 2013.

CAMARGO, Gislene. "Posso falar agora?" as vozes das crianças nos anos iniciais do ensino fundamental. 2014. 89 f. Dissertação (Mestrado em Educação) - Universidade do Extremo Sul Catarinense, Criciúma, 2014.

CARNEIRO, Giane Araújo Pimentel. As práticas educativas familiares no processo de distinção geracional criança/adulto (Catité-BA, 1910-1930). 2011, 146 f. Dissertação (Mestrado em Educação) - Universidade Federal de Minas Gerais, Belo Horizonte, 2011.

CEZÁRIO, Maria Angélica. Infância: idade da (des) razão ou tempo de experiência? 2012. 106 f. Dissertação (Mestrado em Educação) - Pontifícia Universidade Católica de Goiás, Goiânia, 2012.

CNDCT. Conselho Nacional de Desenvolvimento Científico e Tecnológico. Disponível em: https://www.gov.br/cnpq/pt-br/acesso-a-informacao/institucional/institucional. Acesso em: 29 jan. 2021. (2014).

CONCEIÇÃO, Caroline Machado Cortelini. Práticas e representações da institucionalização da infância: Bebês e crianças bem pequenas na creche em Francisco Beltrão/PR (1980/1990). 2014. 253 f. Tese (Doutorado em Educação) - Universidade do Vale do Rio dos Sinos, São Leopoldo, 2014.

CORDEIRO, Andréa Bezerra. Luz e caminho aos pequenos: os primeiros Congressos Americanos da Criança e a Pan-Americanização dos saberes sobre a infância (1916 a 1922). 2015. 379 f. Tese (Doutorado em Educação) - Universidade Federal do Paraná, Curitiba, 2015.

CORRÊA, Liliane da Silva França. A infância em processos judiciais em Belém do Pará: da criminalidade aos discursos jurídico-assistencialistas para a educação do menor desvalido (1890-1930). 2017. 187 f. Dissertação (Mestrado em Educação) - Universidade Federal do Pará, Belém, 2017.

DUARTE, Antônio Valdir Monteiro. Memórias (in)visíveis: narrativas de velhos sobre suas infâncias em Belém do Pará (1900-1950). 137 f. Dissertação (Mestrado em Educação) Universidade Federal do Pará, Belém, 2008.

FRIAS, Bruna Nogueira de. Estratégias educativas para órfãos da Vila e Termo de São João del-Rei (1823-1831). 2017. 160 f. Dissertação (Mestrado - Mestrado em Processos Socioeducativos e Práticas Escolares) - Universidade Federal de São João del-Rei, São João del-Rei, 2017.

GIL, Antonio Carlos. Como elaborar projetos de pesquisa. 4. ed. São Paulo: Atlas, 2002.

GOMES, Lisandra Ogg. Particularidades da infância na complexidade social - Um estudo sociológico acerca das configurações infantis. 2012, $190 \mathrm{f}$. Tese (Doutorado) - Faculdade de Educação, Universidade de São Paulo, São Paulo, 2012. 
GROTTI, Giane Lucélia. História da assistência à criança pobre em Rio Branco - Acre: instituições, sujeitos e ações na década de 1940. 2016. 213 f. Tese (Doutorado em Educação) - Setor de Educação da Universidade Federal do Paraná, Paraná, 2016.

GUALBERTO, Milca Aline Colares. A infância na percepção de crianças em acolhimento institucional no município de Santarém-Pará. 2017. 172 f. Dissertação (Mestrado em Educação) - Universidade federal do Oeste do Pará, Santarém, 2017.

KLEIN, Ligia Regina. Cadê a criança do Ariès que estava aqui? a fábrica comeu... IX Seminário Nacional de Estudos e Pesquisas "História, sociedade e educação no Brasil". João Pessoa: UFPB, 31/07 a 03/08/2012. Disponível em: http://www.histedbr.fe.unicamp.br/acer_histedbr/seminario/seminario9/PDFs/4.26.pdf. Acesso em: 12 ago. 2017. (2012).

LANNA, Nycole Sequeira de. Infâncias disfarçadas: o sentido e o ser criança vivenciados nas escolas da Baixada Fluminense. 2016. 94 f. Dissertação (mestrado em Letras e Ciências Humanas) - Universidade do Grande Rio "Prof. José de Souza Herdy", Duque de Caxias, 2016.

LIMA, Maria do Socorro Pereira. Infância, educação e criança: um estudo histórico-literário nas obras Serões da Mãe Preta e Chove nos Campos de Cachoeira (1897-1920). 2015. 259 f. Tese (Doutorado em Educação) - Universidade Federal do Pará, Belém, 2015.

LIMA, Nicolle Taner de. Os meninos na casa do pequeno jornaleiro: institucionalização, protagonismo e trajetórias (Curitiba, 1960-1978). 2017. 190 f. Dissertação (Mestrado em História) - Universidade do Estado de Santa Catarina, Florianópolis, 2017.

MICELI, Mariana Sant'Ana. Por uma teoria do fazer - Pedagogia do (RE)conhecimento: educar para “crescer direito”. 2010, 445 f. Dissertação (Mestrado em Direito, Estado e Sociedade) - Universidade Federal de Santa Catarina, Florianópolis, 2010.

MIRANDA, Mary Diana da Silva. Crianças negras na Instrução Pública em Cuiabá/MT (1870-1890). 2010. 81 f. Dissertação (Mestrado em Educação). Universidade Federal de Mato Grosso, Cuiabá, 2010.

MOLINA, Adão Aparecido. A produção de dissertações e teses sobre infância na pósgraduação em educação no brasil de 1987 a 2005: aspectos históricos e metodológicos. 2011. 273 f. Tese (Doutorado em Educação) -Universidade Estadual de Maringá, Maringá, 2011.

MOTA, G. L. A concepção de infância nas Orientações Curriculares para a Educação Infantil: um estudo sobre o documento da Prefeitura de São Paulo no período de 2005- 2012. 2017. 153 f. Tese (Doutorado em Psicologia da Educação) - Pontifícia Universidade Católica de São Paulo, 2017.

NOGUEIRA, I. S. C. - O papel do Estado na proteção aos direitos de crianças e adolescentes no Brasil: as especificidades da Constituição Federal, do Estatuto da Criança e do Adolescente e da Lei de Diretrizes e Bases da Educação. 2010, 164 p. Tese (Doutorado em Educação) Faculdade de Filosofia e Ciências, Universidade Estadual Paulista "Júlio de Mesquita Filho", Marília, 2010 
OLIVEIRA, Graziela Zaltron. Políticas de educação para a infância: Concepções subjacentes à legislação. 2010, 89 f. Dissertação (Mestrado em Educação) - Universidade de Passo Fundo, Passo Fundo, 2010.

OLIVEIRA, Maria Luiza Moura. Aldeia Juvenil: duas décadas de contraposição à cultura da institucionalização de crianças e adolescentes pobres em Goiás. 2005. 135 f. Dissertação (Mestrado em Psicologia) - Universidade Católica de Goiás, Goiânia, 2005.

OLIVEIRA, Michelle Araujo de. Concepções de infância e educação nos discursos do periódico a escola - revista official de ensino do Pará (1900 a 1905). 2018. 128 f.

Dissertação (Mestrado em Educação) - Universidade Federal do Pará, Belém, 2018.

PACHECO, Tatiana do Socorro Corrêa. Infância, crianças e experiências educativas no Educandário Eunice Weaver em Belém do Pará (1942-1980). 2017. 248 f. Tese (Doutorado em Educação) - Universidade Federal do Pará, Belém, 2017.

PESSOA, Alba Barbosa. Infância e Trabalho: Dimensões do Trabalho Infantil na Cidade de Manaus (1890-1920). 2010. 180 f. Dissertação (Mestrado em História) - Universidade Federal do Amazonas, Manaus, 2010.

PINHEIRO, Welington da Costa. A infância nas páginas de jornal: discursos (re)produzidos pela imprensa paraense na primeira década do século XX. 2013. 150 f. Dissertação (Mestrado) - Universidade Federal do Pará, Belém, 2013.

PINTO, Layla Mariana Maiante. A cultura da infância nas imediações do bairro santa felicidade do município de maringá: a arte em cena. 2013. 146 f. Dissertação (Mestrado em Educação) - Universidade Estadual de Maringá, Maringá, 2013.

POLETTO, Letícia Borges. Institucionalização de crianças e adolescentes em Caxias do Sul: narrativas sobre as trajetórias de vida de egressos de medida de proteção (1990-2011). 2013. 121 f. Dissertação (Mestrado em Educação) - Universidade de Caxias do Sul, Caxias do Sul, 2013.

PORTAL BRASILEIRO DE DADOS ABERTOS. Coordenação de aperfeiçoamento de pessoal de nível superior-Capes. Disponível em:

https://dados.gov.br/organization/about/coordenacao-de-aperfeicoamento-de-pessoal-denivel-superior-capes. Acesso em 29 jan. 2021.

RIBEIRO, Angelita Soares. Imagens embriagadas, a cruzada das crianças: barbárie e reencantamento do mundo. 2018. 148 f. Tese (Doutorado em Educação) - Universidade Federal de Pelotas, Pelotas, 2018.

SANTANA, Lucirene Ferreira. História da infância e do brinquedo: um olhar nas bonecas Karajá-Ritòkò e Bárbie como artefatos culturais na construção da identidade das meninas da Aldeia. 2014. 173 f. Dissertação (Mestrado) - Pontifícia Universidade Católica, Goiânia, 2014.

SANTOS, Neiva Caetano dos. Assistência à infância como tema de trabalhos apresentados nos Congressos Brasileiros de História da Educação (2000-2015). 2017, 187 f. Dissertação (Mestrado em Ciências) - Faculdade de Filosofia, Ciências e Letras de Ribeirão Preto da Universidade de São Paulo, Ribeirão Preto, 2017.

SANTOS, Sônia Maria Fernandes dos. Criança, cinema e educação: os discursos sobre a infância em produções cinematográficas brasileiras. 2017, 286f. Tese (Doutorado em Educação) - Universidade Federal do Pará, Instituto de Ciências da Educação, Belém, 2017. 
SILVA, Michele Juliana de Carli Anselmo. A revista brasileira de educação: apropriações do discurso acerca dos temas da infância e da história da infância - (1995 a 2010). 2012. 180 f. Dissertação (Mestrado em Educação) - Universidade Estadual de Maringá, Maringá, 2012.

SILVA, Natielly Pryscilla. Concepções de infância e sua relação com o conhecimento psicológico em Goiás: Um recorte histórico. 2019. 204 f. Dissertação (Mestrado em Psicologia) - Universidade Federal de Goiás, Goiânia, 2019.

SILVA, Renato da. "Abandonados e Delinqüentes": A infância sob os cuidados da medicina e do Estado - O Laboratório de Biologia Infantil (1935-1941). 2003. 135 f. Dissertação (Mestrado em História das Ciências da Saúde) - Casa de Oswaldo Cruz - FIOCRUZ, Rio de Janeiro, 2003.

SILVA, Taiane Cristina da. Os filhos da piedade: a exposição na freguesia de Guarapiranga. 2017. 106 f. Dissertação (Mestrado em História) - Universidade Federal de Minas Gerais, Belo Horizonte, 2017.

SOUSA, Flávia Pereira de. Trabalho, Divertimento e Escola: Elementos da história da infância em São Luis de Montes Belos - Go. 2009, 168 f. Dissertação (Mestrado em Educação) - Universidade Federal de Goiás, Goiânia, 2009.

WARDE, Mirian Jorge. Repensando os estudos sociais de história da infância no Brasil. PERSPECTIVA, Florianópolis, v. 25, n. 1, 21-39, jan./jun. 2007. Acesso em: 26 dez. 2017. Disponível em: https://periodicos.ufsc.br/index.php/perspectiva/article/download/1495/1209. (2007).

WEINHARDT, Otávio Augusto Ganzert. Menores problemas, menores soluções: discursos e práticas em torno da infância marginalizada nas décadas finais do Império do Brasil (Curitiba, 1871 - 1889). 2019. 156 f. Dissertação (Mestrado em História) - Universidade Federal do Paraná, Curitiba, 2019.

ZANELLA, Maria Nilvane. Dos fundamentos ideológicos da institucionalização de menores aos fundamentos econômicos da desinstitucionalização de crianças e adolescentes: a extinção da FUNABEM como solução neoliberal. 2018, 582 p. Tese (Doutorado em Educação) Universidade Estadual de Maringá, Maringá, 2018.

ZANIANI, Ednéia José Martins. Sob os auspícios da proteção: Moncorvo Filho e a higienização da infância. 2008. 158 f. Dissertação (Mestrado em Psicologia) - Universidade Estadual de Maringá, Maringá, 2008.

\section{Agradecimentos}

Ao apoio financeiro da Fundação de Amparo à Pesquisa do Estado do Amazonas (FAPEAM), da Universidade Federal do Amazonas (UFAM), da Coordenação de Aperfeiçoamento de Pessoal de Nível Superior (CAPES) e do Conselho Nacional de Desenvolvimento Científico e Tecnológico (CNPq) pela concessão da Bolsa de Iniciação Científica.

Recebido em 30/08/2021. Aceito em 08/11/2021. 


\footnotetext{
${ }^{1}$ A pesquisa supramencionada tinha o prazo de um ano para a entrega dos relatórios parcial e final referente aos resultados alcançados. Assim, destacamos que esta primeira etapa foi concluída e, atualmente, estamos em fase de uma nova análise mediante aprovação de continuidade do projeto.

${ }^{2}$ Cronologicamente falando, a Idade Moderna é o período que se estendeu de 1453, quando se deu a conquista da cidade de Constantinopla pelos otomanos, a 1789, quando ocorreu a tomada da Bastilha pela população parisiense. A visão clássica dos historiadores determinou diversos marcos que são acontecimentos de passagem, isto é, que delimitam o fim de um período e o começo de outro.

${ }^{3}$ É uma fundação do Ministério da Educação (MEC), a qual desempenha papel fundamental na expansão e consolidação da pós-graduação stricto sensu (mestrado e doutorado) em todos as unidades da Federação.

${ }^{4}$ Integrada à Biblioteca Digital Brasileira de Teses e Dissertações (BDTD), que tem por objetivo reunir, em um só portal de busca, as teses e dissertações defendidas nas instituições brasileiras de ensino e pesquisa e por brasileiros no exterior.

${ }^{5}$ Dados coletados do Portal da CAPES, 2020.

${ }^{6}$ Dados coletados do Portal da CAPES, 2020.

${ }^{7}$ Dados coletados do Portal da CAPES, 2020.

${ }^{8}$ Dados coletados do Portal da CAPES, 2020.

${ }^{9}$ Relacionado à "[...] falta de hospitais para que as crianças pudessem nascer sob a assistência de profissionais habilitados e de acompanhamento em seus primeiros anos de vida; ausência de um programa de educação formal que atendesse à demanda, pois se considerava grande o índice de analfabetismo, tanto em meio às crianças, como entre jovens e adultos; a pobreza, que gerava uma série de outras limitações e dificuldades”, que são alguns elementos que compuseram essa conceituação (GROTTI, 2016, p. 15).

${ }^{10}$ A pesquisadora destaca o Departamento Nacional da Criança (DNCr); a Legião Brasileira de Assistência (LBA); a Comissão Territorial da LBA; o Instituto de Amparo Social; a Instituição de Assistência Social Darcy Vargas; a Sociedade Plácido de Castro; novamente a Legião Brasileira de Assistência e a Sociedade Plácido de Castro bem como o próprio Estado, a escola, a pré-escola e a família.

${ }^{11}$ Estamos todos nos preparando para um novo instante. O presente já se tornou passado e vivemos no vislumbre do futuro. Assim, crianças e adultos vivem um constante "vir a ser" (o que viremos a ser). Todavia, socialmente falando, evidenciamos que essa condição é limitadora apenas as crianças. Nesse sentido, Oliveira (2010, p. 81) questiona: “esse 'vir a ser' não retira do adulto seu papel de ator social, de sujeito, logo, por que tiraria da criança?". ${ }^{12}$ As práticas higienistas consistiam na disseminação de "[...] noções de higiene e empreendiam campanhas contra a mortalidade infantil, os fatores de degeneração da raça imputados a algumas doenças e vícios, combatiam a criminalidade e outros desvios comportamentais" (ZANIANI, 2008, p. 12).

${ }^{13}$ Bonecas produzidas pelas mulheres indígenas Karajás, feita em cerâmica, que reproduzem a forma humana e a representação da fauna. Desde 25 de janeiro de 2012, foi conferido a elas o título de Patrimônio Cultural Brasileiro. Disponível em: http://portal.iphan.gov.br/noticias/detalhes/1190/bonecas-karaja-novo-patrimonio-culturalbrasileiro.

${ }^{14}$ A pesquisadora relacionou que eles eram tidos como abandonados em razão do "[...] Código de Menores de 1927, que determinava em seu artigo 31, a possibilidade de suspensão ou perda do pátrio poder: a partir do momento em que o menino estivesse interno, seus pais teriam suspensa sua guarda, que ficaria a cargo do Estado, isto é, o menino seria considerado "abandonado" mesmo que temporariamente, já que sob a tutela do Juizado" (LIMA, 2017, p. 157-158).

${ }^{15}$ Dados coletados do Portal da CAPES, 2020.
} 